\title{
COP and Economic Analysis of the Heat Recovery from Waste Water using Heat Pumps
}

\author{
Jozsef Nyers \\ Obuda University Budapest, Hungary \\ Szent Istvan University Gödöllö-Budapest, Hungary \\ Subotica Tech, Marko Oreskovic 16, 24000 Subotica, Serbia \\ e-mail: nyers@uni-obuda.hu
}

\begin{abstract}
This article presents a newly designed and realized system for heat recovery from waste water. The waste water is the heat source, the temperature of which is about 44-49 ${ }^{\circ} \mathrm{C}$. The heat recovery process is performed using a plate heat exchanger and two heat pumps. The mentioned components are serially linked. The heat sink is clean water, which is pumped from a 40 meter deep well and is heated up from $13-14{ }^{\circ} \mathrm{C}$ to $50-55^{\circ} \mathrm{C}$. Waste water is cooled down from $44-49^{\circ} \mathrm{C}$ to $13-14^{\circ} \mathrm{C}$. The mass flow rate of the clean and waste water is approximately the same. This heat recovery process reaches a significant coefficient of performance (COP) with 6.03-6.5 meaning that 83-85\% of the energy demand for heating clean water is provided by the recovery process and electric energy is consumed only for 17-15\%. From the aspect of energy efficiency: the plate heat exchanger participates by about 49\%, the low temperature heat pump by 30\%, the high temperature heat pump by $21 \%$ in the heat recovery.
\end{abstract}

Keywords: heat recovery; heat pump; waste water; COP; payback period

\section{NOMENCLATURE}

$\dot{q}$ : heat flux, $\mathrm{W}$

$Q:$ total heat, $\mathrm{J}$

$\dot{m}$ : mass flow rate, $\mathrm{kg} / \mathrm{s}$

$C_{p}$ : specific heat, $\mathrm{p}=$ const., $\mathrm{J} / \mathrm{kgK}$

$P=$ performance or power, $\mathrm{W}$

$T$ : temperature, $\mathrm{K},{ }^{\circ} \mathrm{C}$

$\Delta T$ : temperature difference, $\mathrm{K},{ }^{\circ} \mathrm{C}$ $C O P$ : coefficient of performance

$P H E$ : plate heat exchanger

HP1: low-temperature heat pump HP2: high-temperature heat pump $H R S$ : heat recovery system

\author{
Greek symbols \\ $\Delta$ : different, \\ $\tau$ : time duration,
}

\section{Subscripts and Superscripts}

$w:$ water,

$i$ : input,

$o:$ output,

e : evaporator,

$\mathrm{c}$ : condenser,

$h p:$ heat pump,

phe or ex: plate heat exchanger, 
$r s:$ recovery system,

1 : first heat pump, filled with $\mathrm{R} 407 \mathrm{C}$,

2 : second heat pump, filled with $\mathrm{R}$ $134 \mathrm{a}$,

$p:$ pressure,

pump : centrifugal pump,

comp : compressor te : total electric power demand,

dis : dissipation,

save : save,

$\max$ : maximum,

$\min$ : minimum.

\section{Introduction}

In the present, world-leading scientific journals only a few scientific-research articles can be found related to heat recovery systems applying some kind of a heat pump. Fangtian Sun et al. [1] presented a new waste heat district heating system based on ejector heat exchangers -EHE and absorption heat pumps -AHP. The goal was to decrease heating energy consumption of an existing combined heat-power system by recovering waste heat of exhausted steam from a steam turbine. A new ejector heat exchanger based on ejector refrigeration cycle (absorption heat pump) was developed and used. The new EHE+AHP system can decrease consumption of steam extracted from a steam turbine by $41.4 \%$ and increase heat capacity of the existing heating network by $66.7 \%$ without changing the mass flow rate of circulating water. The heating cost of the new EHE+AHP system is $8.62 \mathrm{U} / \mathrm{GJ}$ less than that of traditional systems. The payback period of the investment was about 2 years. Jian Sun et al. [2] the same group of authors [1] published this article. The problem was the same, but in this study they focused on the mathematical description and measurement of the process in the heat recovery unit (HRU). HRU is composed of a condenser and absorption heat pump. The heat source is exhausted steam from the steam turbine and the heat sink is a combined heat-power system, CHP. Mathematical simulation is validated through measurements. It was found that the COP of the AHP 1.74 and $25 \mathrm{MW}$ heat from exhausted steam is recovered by the HRU. Marija S. Todorovic and Jeong Tai Kim [3] analyzeda cost-effective technical solution for replacing fossil fuel and electricity with solar energy for water heating for different purposes (for pools, sanitary water, washing) in a spa. Bicui Ye et al. [4] proposed a new open absorption heat pump system in order to improve the thermal efficiency of the drying process. The aim was to recover the latent heat from exhausted moist gas. A mathematical model was established in order to analyze the performance of the new system. Simulation results indicated an improved COP of the new system compared to that of the double-stage close absorption heat pump system. The COP of the new system varied from 1.52 to 1.97 and the efficiency of heat recovery varied from $15.1 \%$ to $54.8 \%$ when the temperature of heat source varied from 
$135{ }^{\circ} \mathrm{C}$ to $175{ }^{\circ} \mathrm{C}$ and saturated steam of $100{ }^{\circ} \mathrm{C}$ was produced. Ming Qu et al. [5] dealt with heat recovery from flue gases exiting from the gas boiler. These gases contain large amounts of water vapor and a large amount of heat at high temperatures, $150-200{ }^{\circ} \mathrm{C}$. For that reason the efficiency varied,only from $70 \%$ to $80 \%$. Applying an absorption heat pump, part of the latent heat from the flue gas can be recovered. A mathematical model was created in order to test the COP of the HRS. Results of the model were verified by measurements on the performed system. The results are presented in the diagrams and indicate significant improvements of the COP. Zhao Yang et al. [6] presented a novel "travellingwave thermo-acoustic heat pump" for the production of high temperature steam from 80 to $200{ }^{\circ} \mathrm{C}$. This system comprises three linear pressure wave generators which are coupled with three heat pumps into one single closed loop. Theoretical simulations were performed at varied waste-heat temperatures $\left(40-70{ }^{\circ} \mathrm{C}\right)$ and different hot-end temperatures $\left(120-150{ }^{\circ} \mathrm{C}\right)$. The computing results show that this new heat pump system has a high efficiency of about $50 \%-60 \%$ related to Carnot.

Jozsef Nyers et al. [7], [8], [9] in earlier works has dealt with heat pumps and using the heat pumps for heating-cooling and heat recovery.

Analyzing the literature above the following content can be summarized: in the articles [1], [2], [6] the heat is recovered from exhausted steam of a steam turbine by applying the absorption heat pumps or in [6] a travelling-wave thermo-acoustic heat pump. Authors presented cases [4], [5], when waste heat is recovered from moist gases using also absorption heat pumps. In the present article the goal is the same as mentioned before, but the solution and realization are different. Heat is recovered from waste water using a plate heat exchanger and vapor-compression heat pumps.

It can be seen that in the contemporary energy sector that heat recovery occupies a more and more significant place. By applying the heat recovery system enormous energy savings are achieved, usually over $80 \%$. The payback period of the investment is very short. In Subotica, Serbia an opportunity appeared for designing and realizing a heat recovery system for a jeans factory.

During the production process washing of jeans is necessary. For washing, a large quantity of hot water, $5220 \mathrm{~kg} / \mathrm{h}$ at atemperature from $50^{\circ} \mathrm{C}$ to $55^{\circ} \mathrm{C}$ is needed. Clean water for the process is taken from two more than 40 meter deep wells. For the water pumping centrifugal pumps are applied. The temperature of the clean well water is about $13.8^{\circ} \mathrm{C}$. For heating up this quantity of clean well water from $13.8{ }^{\circ} \mathrm{C}$ to $50{ }^{\circ} \mathrm{C}$ or $55^{\circ} \mathrm{C}$, approximately $220-248 \mathrm{~kW}$ power is needed. Applying the heat recovery system $85 \%$ of $248 \mathrm{~kW}$ power demand is recovered from the waste water. The achieved energy efficiency is very high, coefficient of performance reaches a maximum value of $\mathrm{COP}_{\max }=6.5$ or a minimum $\mathrm{COP}_{\min }=$ 6.03 . 
The system components are serially linked and therefore during the operation, the quantity of clean water entering the washing machine is approximately equal to the waste water leaving the washing machine simultaneously. Temperature of the waste water which leaves the system ranges from $44^{\circ} \mathrm{C}$ to $49^{\circ} \mathrm{C}$. While applying the heat recovery system the heat from the waste water is mostly transferred to the clean water. The temperature and mass flow rate of the incoming clean water and the outgoing waste water is nearly the same (about $13-14^{\circ} \mathrm{C}$ ).

System components that participate in the heat recovery system are: plate heat exchanger, heat pump for low (R 407C) and heat pump for high temperatures $(\mathrm{R}$ 134a). Study of system's energy efficiency based on the total coefficient of performance and the partial COP of individual components was determined, as well. The aim of partial analysis of COP was to find out the participation of individual components in the total COP. Analysis and definition of partial COP is the first step to improve the system's energy and economic efficiency.

Indeed, the dimensioning of the thermal components was conducted classically, without optimization. The task of further research is to find the optimal structure and dimensions of the system's thermal and energy components in order to improve the energy and economic efficiency of the new heat recovery system.

\section{Physical Model of the Recovery System}

\subsection{Structure of the Recovery System}

The heat recovery system is composed of the following components:

- (1) Two 40 meter deep wells as the source of clean water,

- (2) Two centrifugal pumps for forwardingand pumping the clean water from the well,

- (3) Plate heat exchanger,

- (4) Heat pump for low temperatures,

- (5) Heat pump for high temperatures,

- (6) Tank for hot clean water,

- (7) Washing machines,

- (8) Tank for hot waste water,

- (9) Two centrifugal pumps for pumping and transporting the waste water,

- (10) Sewer system for waste water draining,

- System for automatic control,

- System of measuring instruments. 


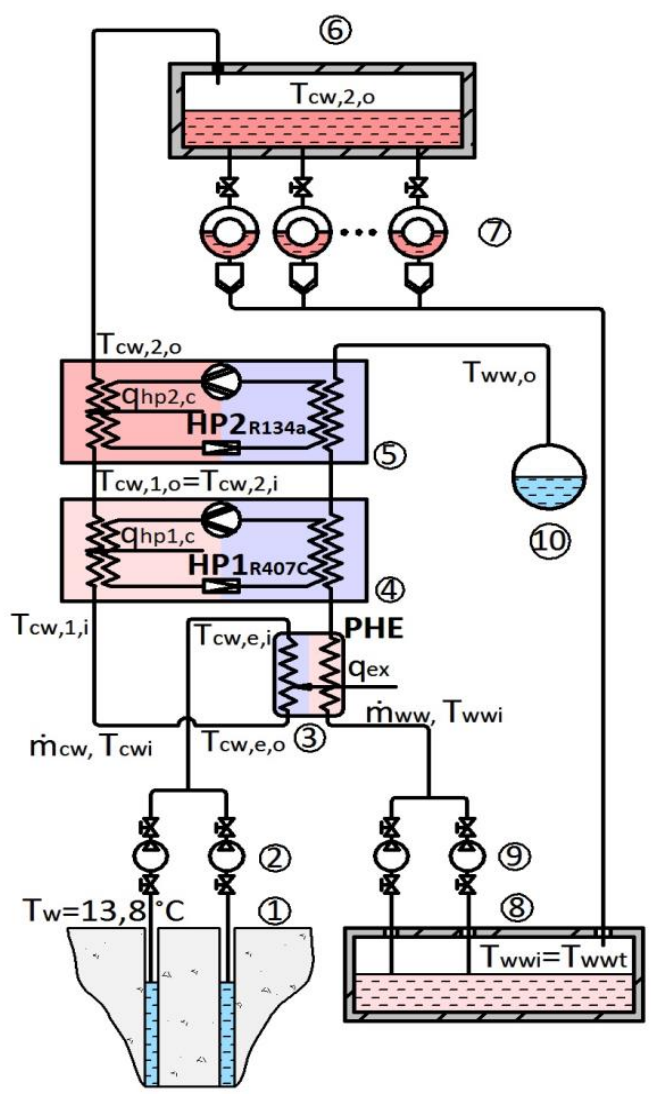

Figure 1

The functionalscheme of the heat recovery system with system's parameters

\section{System Operation}

\subsection{General Description}

The main energy components of the heat recovery system are the plate heat exchanger and the heat pump for higher and lower temperature range.

The first stage of heat recovery is realized in the counter flow plate heat exchanger. On one side of the exchanger clean cold water flows from the well, while on the other side, hot waste water flows from the washing machine. For both fluids, the flow energy is provided by centrifugal pumps. As a result, heat is recovered from the hot waste water to cold clean water. 
The second stage of the heat recovery is realized in the first heat pump. The clean water flows through a shell tube condenser, while the waste water flows through the evaporator of the heat pump. The refrigeration circuit by applying mechanical work transports the heat from the waste water to the clean water.

The third stage of heat recovery occurs in the second heat pump. The clean water from the first pump's condenser flows through the condenser of the second heat pump. The waste water from the first pump's evaporator also flows through the evaporator of the second heat pump. The refrigeration circuit transports the heat between waste and clean water.

The clean heated water is gathered in the thermal insulated tank, while the cooled waste water is released into the sewer after filtration.

The clean hot water tank is elevated $5 \mathrm{~m}$ and therefore water by free fall can flow into the washing machine. From the washing machine the water is then released into the pipelines and by free fall it flows into the tank. The tank is placed on the ground. Pumpingthe clean water from the well is realized by the use of centrifugal pumps.

\subsection{Supervision of the System}

For the time being the supervision of the entire system is done visually with the exception of the heat pumps, supervision of which is automated.

Supervision is realized by measuring instruments: thermometers and manometers.

The manometers are built in the inlet pipeline of the pumps, in front of the plate surface exchanger.

The thermometers measure the water temperature in both tanks, in front of and after the plate exchanger, as well as the temperature of the incoming and outgoing water in both heat pumps.

\section{Mathematical Model}

\subsection{Introduction}

When analyzing the heat recovery system, the basic question is the energy and economic efficiency of the process. The answer can be found by determining the total and partial COP of the system. This means the quantity of total or partial recovered heat in all heat exchangers and all the invested mechanical work necessary for driving the electric motors should be found. 
For the analysis adequate mathematical model is required. The mathematical description is conducted for the stationary operation mode of the heat recovery process.

\subsection{Approximations and Assumptions}

During the steady operation mode of the system all parameters are in a greater or lesser extent change. Some of them can be considered without greater error constant. For example: Mass flow rate of the clean and waste water can be considered permanent because the geometry of the pipe network and the power of centrifugal pumps in the operation manner do not change.

Hydraulic resistance of the pipeline due to unchanging geometry is constant.

Power of the centrifugal pumps is unchangeable.

Temperature of well wateris non-variable. Therefore, the input temperature of well water in the plate heat exchanger is constant.

The time variable system parameters are:

1) The clean hot water outlet temperature from the tank, which is variable. The reason, the clean hot water consumption from the tank is stochastic, depends on the simultaneity of filling of the four washing machines. When the consumption rises, the quantity of the cold water will rise as well; this in turn lowers the temperature of the clean hot water.

2) Due to the temperature variation of hot clean water the temperature of the waste water that enters and leaves the washing machines also varies.

3) Varies the input as well as output temperature of the waste water on the input and output of the heat exchangers, as well.

\subsection{Heat Transfer in the Recovery System}

The heat transfer in the recovery system is realized in three stages, in the plate exchanger, as well as, in the first and the second heat pump's heat exchangers (evaporators and condensers).

The mentioned components of the system are serially linked; therefore the total heat flux of the recovery system is sum of three partial fluxes:

$\dot{q}_{r s}=\frac{\sum_{i=1}^{3} Q_{i}}{\tau}$

After substitution

$\dot{q}_{r s}=\dot{q}_{e x}+\dot{q}_{1 h p, c}+\dot{q}_{2 h p, c}$ 
Where:

$Q_{i}[J]$ - Total transferred heat in heat exchangers for $\tau$ time

$\tau$ [sec ]- Time duration,

$\dot{q}_{r s}[W]$ - Total heat flux in the heat exchangers,

$\dot{q}_{e x}[W]$ - Heat flux in the plate heat exchanger,

$\dot{q}_{1 h p, c}[W]$-Heat flux in the condenser of the first heat pump with R 407C,

$\dot{q}_{2 h p, c}[W]-$ Heat flux in the condenser of the second heat pump with R 134a.

\subsection{Heat Transferred from the Waste Water}

Waste water is the heat source in the recovery process. Due to the heat transfer in the plate heat exchanger and in the evaporators of heat pumps the waste water's temperature decreases.

Recovered heat flux from the waste water in all heat exchangers is the following.

$\dot{q}_{w w}=C_{p w} \cdot \dot{m}_{w w} \cdot \Delta T_{w w}[W]$

The temperature difference between input and output temperatures of the waste water in all serial linked heat exchangers is:

$\Delta T_{w w}=T_{w w, i}-T_{w w, o}$

Where:

$C_{p w}\left[\frac{\mathrm{J}}{\mathrm{kgK}}\right]$ - Isobaric specific heat of the waste water,

$\dot{m}_{w w}\left[\frac{\mathrm{kg}}{\mathrm{s}}\right]$ - Mass flow rate of the waste water throughout the system,

$T_{w w, i}[\mathrm{~K}]-$ Temperature of the waste water on the input of the plate heat exchanger,

$T_{w w, o}[\mathrm{~K}]-$ Temperature of the waste water on the output of the second heat pump evaporator. 


\subsection{Heat Transferred to the Clean Water}

During the recovery process by applying the plate heat exchanger and the heat pumps the heat-energy from the waste water is recovered which heats up the clean water from $13-14{ }^{\circ} \mathrm{C}$ to $50-55^{\circ} \mathrm{C}$.

Heat flux equals the increment of the clean water enthalpy

$\dot{q}_{c w}=C_{p w} \cdot \dot{m}_{c w} \cdot \Delta T_{c w}$

Increase ofthe clean water temperature

$\Delta T_{c w}=T_{c w, i}-T_{c w, o}$

Where:

$C_{p w}\left[\frac{\mathrm{J}}{\mathrm{kgK}}\right]$ - Isobaric specific heat of the clean water,

$\dot{m}_{c w}\left[\frac{\mathrm{kg}}{\mathrm{s}}\right]$ - Mass flow rate of the clean water,

$T_{c w, i}[\mathrm{~K}]-$ Input temperature of the clean water,

$T_{c w, o}[\mathrm{~K}]-$ Output temperature of the clean water.

\subsection{Electric Power Demand}

Electric power demand of system equals the electricity demand of the electric motors for driving the compressors and centrifugal pumps is as follows.

$P_{t e}=\sum_{1}^{2} P_{\text {comp }}+\sum_{1}^{2} P_{w \text { pump }}+\sum_{1}^{2} P_{c \text { pump }}$.

After substitution the partial electricity demand:

$P_{t e}=P_{\text {compl }}+P_{\text {comp } 2}+P_{w \text { pumpl }}+P_{w \text { pump } 2}+P_{\text {c pump } 3}+P_{c \text { pump } 4}$.

Where:

$P_{\text {comp }}[\mathrm{W}]-$ Power demand of the electric motors for driving the compressors.

$P_{w, c, p u m p}[\mathrm{~W}]-$ Power demand of the electric motors for driving the well and the centrifugal pumps. 


\subsection{Coefficient of Performance-COP}

The coefficient of performance, COP is a ratio between the heat fluxes transferred tothe clean hot water and the electric power demand of all electric motors for driving the compressors and centrifugal pumps.

$$
C O P=\frac{q_{c w}}{P_{t e}}
$$

After substitution all the transferred heat fluxes and electric power demand of all electric motors

$$
C O P=\frac{C_{p v} \cdot \dot{m}_{c w} \cdot \Delta T_{c w}}{\sum_{l}^{2} P_{c o m p}+\sum_{l}^{2} P_{w \text { pump }}+\sum_{l}^{2} P_{c \text { pump }}}
$$

Determination of the COP is possible through the evaporators or in other words through the waste water in the evaporators, as well. In this case, the total heat flux is calculated so that to the heat flux $\left(\mathrm{q}_{\mathrm{ww}}\right)$ of the waste water in the evaporators is added to the consumed electric power of both the compressors $\left(\mathrm{P}_{\text {comp }}\right)$ and two centrifugal pumps $\left(\mathrm{P}_{\mathrm{c} \text { pump }}\right)$ in hot water circuit $(11)$.

$$
C O P=\frac{q_{w w}+\sum_{1}^{2} P_{\text {comp }}+\sum_{1}^{2} P_{c \text { pump }}}{P_{\text {te }}}
$$

After substitution

$$
C O P=\frac{C_{p v} \cdot \dot{m}_{w w} \cdot \Delta T_{w w}+\sum_{l}^{2} P_{c o m p}+\sum_{l}^{2} P_{c \text { pump }}}{\sum_{l}^{2} P_{c o m p}+\sum_{l}^{2} P_{w \text { pump }}+\sum_{l}^{2} P_{c \text { pump }}}
$$

\subsection{Partial COPof the Individual Components}

In this chapter the partial participation of individual components in the total COP was determined. Particularly, the COP of the heat exchanger, the first and second heat pump is determined in order to see exactly the percentage contribution and the energy efficiency of the components.

The total heat flux which clean water receives is the sum of the partial fluxes realized in the heat exchanger, and the condensers of the first and second heat pump.

$\dot{q}_{r s}=\dot{q}_{e x}+\dot{q}_{1 h p, c}+\dot{q}_{2 h p, c}$ 
Heat flux in the plate heat exchanger

$\dot{q}_{e x}=C_{p v} \cdot \dot{m}_{c w} \cdot\left(T_{c w, e, o}-T_{c w, e, i}\right)$

Heat flux in the 1. heat pump's heat exchanger i.e. in the condenser

$\dot{q}_{1 h p, c}=C_{p v} \cdot \dot{m}_{c w} \cdot\left(T_{c w, 1, o}-T_{c w, 1, i}\right)$

Heat flux in the 2. heat pump's heat exchanger i.e. in the condenser

$\dot{q}_{2 h p, c}=C_{p v} \cdot \dot{m}_{c w} \cdot\left(T_{c w, 2, o}-T_{c w, 2, i}\right)$

Total coefficient of performance of the system

$$
\begin{aligned}
& C O P=\frac{\dot{q}_{r s}}{P_{t e}} \\
& C O P=\frac{\dot{q}_{e x}+\dot{q}_{1 h p, c}+\dot{q}_{2 h p, c}}{P_{t e}} \\
& C O P=\frac{\dot{q}_{e x}}{P_{t e}}+\frac{\dot{q}_{1 h p, c}}{P_{t e}}+\frac{\dot{q}_{2 h p, c}}{P_{t e}}
\end{aligned}
$$

Partial coefficients of performance of the components

$$
\begin{aligned}
& C O P_{e x}=\frac{\dot{q}_{e x}}{P_{t e}}[-] \text { of the heat exchanger } \\
& C O P_{1 h p, c}=\frac{\dot{q}_{1 h p, c}}{P_{t e}}[-] \text { of the } 1 \text { heat pump } \\
& C P_{2 h p, c}=\frac{\dot{q}_{2 h p, c}}{P_{t e}}[-] \text { of the } 2 \text { heat pump }
\end{aligned}
$$

Percentage share of partial COPs, in the total COP.

$$
\begin{aligned}
& C O P_{e x, \%}=\frac{C O P_{e x}}{C O P} \cdot 100[\%] \text { of the heat exchanger } \\
& C O P_{l h p, c, \%}=\frac{C O P_{l h p, c}}{C O P} \cdot 100[\%] \text { of the } 1 \text { heat pump } \\
& C O P_{2 h p, c, \%}=\frac{C O P_{2 h p, c}}{C O P} \cdot 100[\%] \text { of the } 2 \text { heat pump }
\end{aligned}
$$


Total coefficient of performance equalsthe sum of partial coefficients of performance

$C O P=C O P_{e x}+C O P_{1 h p, c}+C O P_{2 h p, c}[-]$

\subsection{Heat Dissipation during the Process}

During the operation of the system through each of the components' surface heat dissipation occurs into the colder air of the environment. The quantity of the dissipated heat flux is approximately equal to the difference between the clean hot water fluxthat leaves the condenser of 2 . heat pump and the waste water flux which enters the heat plate exchanger.

Dissipate heat flux in the whole heat recovery system can be calculated as follows

$$
\begin{aligned}
& \dot{q}_{d i s}=\dot{q}_{c w, o}-\dot{q}_{w w, i} \\
& \dot{q}_{d i s}=C_{p w} \cdot \dot{m}_{c w} \cdot T_{c w, o}-C_{p w} \cdot \dot{m}_{w w} \cdot T_{w w, i}
\end{aligned}
$$

In fact, in steady operation mode of system, mass flow rate is unchangeable. Therefore, the mass flow rate of the clean and the waste water is approximately equal.

$$
\dot{m}_{w} \cong \dot{m}_{w w} \cong \dot{m}_{c w}
$$

After substitution the dissipate heat

$$
\dot{q}_{d i s}=C_{p w} \cdot \dot{m}_{w} \cdot\left(T_{c w, o}-T_{w w, i}\right)
$$

\subsection{Energy Savings as a Percentage}

Saved energy flux is equal to the difference between obtained and invested energies

$$
\dot{q}_{\text {save }}=\dot{q}_{w c}-P_{t e}
$$

Energy savings as a percentage is obtained if the saved energy flux is divided by the energy flux demand.

$$
\frac{\dot{q}_{\text {save }}}{\dot{q}_{w c}} \cdot 100=\frac{\dot{q}_{w c}-P_{t e}}{\dot{q}_{w c}} \cdot 100=\left(1-\frac{P_{t e}}{\dot{q}_{w c}}\right) \cdot 100
$$

After substituting the COP

$$
\left(1-\frac{1}{C O P}\right) \cdot 100[\%]
$$




\section{Numerical Energy Analysis}

\subsection{Introduction}

Measurement of the system parameters has been carried out during steady-state operation mode of the heat recovery system. All vital parameters are measured in order to determine the energy efficiency through the coefficient of performance (COP) and the payback period of the investment.

The measuring is conducted by applying:

- Glass thermometers filled with alcohol, with a resolution of $0.1^{\circ} \mathrm{C}$ and measurement range from- 10 to $+110^{\circ} \mathrm{C}$. Figure 2

- Turbine flow meter: dimension 5/4", accuracy $2 \%$ at nominal volumetric flow rate of $5 \mathrm{~m}^{3} / \mathrm{h}$. Figure 3 .

- Manual electrical Watt meter.

\subsubsection{Unchangeable Measured Parameters of the System}

- Mass flow rate of the clean and waste water

$$
\dot{m}_{c w} \cong \dot{m}_{w w} \cong 87[\mathrm{~kg} / \mathrm{min}]=5220[\mathrm{~kg} / \mathrm{h}]
$$

- Temperature of the clean well water $T_{c w i}=13.8\left\lfloor\left\lfloor{ }^{o} \mathrm{C}\right\rfloor\right.$

- Electric power demand of the well pumps $P_{w \text { pump }}=1359[\mathrm{~W}]$

- Electric power demand of the circulation pumps $P_{c \text { pump }}=906[\mathrm{~W}]$

\section{Numerical Results}

\subsection{COP Maximum}

- Temperature of the clean water, flows out of the condenser $\mathrm{T}_{\mathrm{cw}, \mathrm{o}}=54.7\left[{ }^{\circ} \mathrm{C}\right]$

- Temperature of the waste water at the input of plate heat exchanger $T_{w w, i}=48.8$ $\left[{ }^{o} \mathrm{C}\right]$

- Electric power demand of the heat pump1. $P_{h p l}=19338[\mathrm{~W}]$

- Electric power demand of the heat pump2. $P_{h p 2}=15337$ [W]

Recovered heat to the clean water

$$
\dot{q}_{c w}=C_{p v} \cdot \dot{m}_{c w} \cdot \Delta T=1.163 \frac{W h}{k g^{o} \mathrm{C}} 5220 \frac{\mathrm{kg}}{\mathrm{h}}(54.7-13.8)^{\circ} \mathrm{C}
$$


$\dot{q}_{c w}=248298[\mathrm{~W}]$

Total electrical power demand

$$
\begin{aligned}
& P_{t e}=\sum_{1}^{2} P_{\text {comp }}+\sum_{1}^{2} P_{\text {w pump }}+\sum_{l}^{2} P_{c \text { pump }} \\
& P_{t e}=19338+15337+2 \cdot 1359+2 \cdot 906=38205[\mathrm{~W}]
\end{aligned}
$$

COP maximum of recovery system based on measured values

$$
\begin{aligned}
& C O P_{\text {max }}=\frac{q_{c w}}{P_{t e}}=\frac{248298[\mathrm{~W}]}{38205[\mathrm{~W}[}=6,499 \approx 6.5 \\
& C O P_{\text {max }}=6.499 \approx 6.5
\end{aligned}
$$

\subsection{COP Minimum}

- Temperature of the clean water which flows out of the condenser $T_{c w, o}=51.6$ $\left[{ }^{\circ} \mathrm{C}\right]$

- Temperature of the waste water on the input of the plate heat exchanger $T_{w w, i}=44.5\left[{ }^{\circ} \mathrm{C}\right]$

- Electric power demand of the heat pump1. $P_{h p l}=17847$ [W]

- Electric power demand of the heat pump2. $P_{h p 2}=14168$ [W]

Recovered heat to the clean water

$$
\begin{aligned}
& Q_{C W}=C_{p v} \cdot \dot{m}_{C W} \cdot \Delta T=1.163 \frac{\mathrm{Wh}}{\mathrm{kg}^{\circ} \mathrm{C}} 5220 \frac{\mathrm{kg}}{\mathrm{h}}(50.1-13.8)^{\circ} \mathrm{C} \\
& Q_{c w}=220372[\mathrm{~W}]
\end{aligned}
$$

The value of the total invested electrical power:

$$
\begin{aligned}
P_{t e} & =\sum_{1}^{2} P_{\text {comp }}+\sum_{1}^{2} P_{\text {w pump }}+\sum_{1}^{2} P_{c \text { pump }} \\
P_{t e} & =17847+14168+2 \cdot 1359+2 \cdot 906[\mathrm{~W}] \\
P_{t e} & =36545[\mathrm{~W}]
\end{aligned}
$$

$\mathrm{COP}$ of the recovery system based on the measured values.

The value ofenergy efficiency ratio of recovery:

$$
\begin{aligned}
& C O P_{\text {min }}=\frac{q_{c w}}{P_{t e}}=\frac{208928[\mathrm{~W}]}{34675[\mathrm{~W}[}=6,03 \\
& C O P_{\text {min }}=6.03 \approx \mathbf{6 . 0}
\end{aligned}
$$




\subsection{Partial COPs}

\subsubsection{Partial COP of Heat Plate Exchanger}

- Input temperature of clean water at the entrance of the plate heat exchanger $\mathrm{T}_{\mathrm{ex}, \mathrm{i}}=13.8^{\circ} \mathrm{C}$

- Output temperature of clean water at the exit of the plate heat exchanger $\mathrm{T}_{\mathrm{ex}, \mathrm{i}}=33.9^{\circ} \mathrm{C}$

$$
\begin{aligned}
& C O P_{e x}=\frac{\dot{q}_{e x}}{P_{t e}}=\frac{C_{p w} \cdot \dot{m}_{c w} \cdot \Delta T_{c w}}{P_{t e}}=\frac{1.163 \frac{\mathrm{Wh}}{\mathrm{kg}^{o} \mathrm{C}} 5220 \frac{\mathrm{kg}}{\mathrm{h}}(33.9-13.8)^{\circ} \mathrm{C}}{38205[\mathrm{~W}]}=3.1939[-] \\
& C O P_{e x, \%}=\frac{C O P_{e x}}{C O P} \cdot 100=\frac{3.1939}{6.499} \cdot 100 \%=49.15[\%]
\end{aligned}
$$

\subsubsection{Partial COP of Heat Pump1}

- Input temperature of clean water at the entrance of the heat pump1 condenser $\mathrm{T}_{1 \mathrm{ht}, \mathrm{c}}=33.9^{\circ} \mathrm{C}$

- Output temperature of clean water at the exit of the heat pump1 condenser $\mathrm{T}_{1 \mathrm{ht}, \mathrm{c}}=46.2^{\circ} \mathrm{C}$

$$
\begin{aligned}
& C O P_{l h p, c}=\frac{\dot{q}_{l h p, c}}{P_{t e}}=\frac{C_{p w} \cdot \dot{m}_{c w} \cdot \Delta T_{c w}}{P_{t e}}=\frac{1.163 \frac{W h}{\mathrm{~kg}^{o} \mathrm{C}} 5220 \frac{\mathrm{kg}}{\mathrm{h}}(46.2-33.9)^{\circ} \mathrm{C}}{38205[\mathrm{~W}]}[-] \\
& C O P_{l h p, c}=1.9545[-] \\
& C O P_{l h p, c, \%}=\frac{C O P_{l h p, c}}{C O P} \cdot 100=\frac{1.9545}{6.499} \cdot 100 \%=30.03[\%]
\end{aligned}
$$

\subsubsection{Partial COP of Heat Pump2}

- Input temperature of clean water at the entrance of the heat pump2 condenser $\mathrm{T}_{2 \mathrm{ht}, \mathrm{c}}=46.2^{\circ} \mathrm{C}$

- Output temperature of clean water at the exit of the heat pump2 condenser $\mathrm{T}_{2 \mathrm{ht}, \mathrm{c}}=54.7^{\circ} \mathrm{C}$

$$
\begin{aligned}
& \mathrm{COP}_{2 h p, c}=\frac{\dot{q}_{2 h p, c}}{P_{t e}}=\frac{C_{p w} \cdot \dot{m}_{c w} \cdot \Delta T_{c w}}{P_{t e}}=\frac{1.163 \frac{\mathrm{Wh}}{\mathrm{kg}^{o} \mathrm{C}} 5220 \frac{\mathrm{kg}}{\mathrm{h}}(54.7-46.2)^{o} \mathrm{C}}{38205[\mathrm{~W}]}[-] \\
& \mathrm{COP}_{2 h p, c}=1.3511[-] \\
& \mathrm{COP}_{2 h p, c, \%}=\frac{C O P_{2 h p, c}}{C O P} \cdot 100=\frac{1.3511}{6.499} \cdot 100 \%=20.79[\%]
\end{aligned}
$$




\subsubsection{Validity of COP}

Total COP of heat recovery system can be calculated directly or through partial COPs the final result is the same. The proof is next.

$$
\begin{aligned}
& C O P=C O P_{e x}+C O P_{1 h p, c}+C O P_{2 h p, c} \\
& C O P=3.1939+1.9545+1.3511=6.499 \quad[-] \\
& C O P_{\%}=49.15+30.03+20.79=99.97 \quad[\%]
\end{aligned}
$$

\subsubsection{Saved Energy in Percentage}

Maximum of saving

$\left(1-\mathrm{COP}^{-1}\right) \cdot 100=\left(1-6.5^{-1}\right) \cdot 100[\%]=85 \%$

Minimum of saving

$$
\left(1-\mathrm{COP}^{-1}\right) \cdot 100=\left(1-6.0^{-1}\right) \cdot 100[\%]=83.3 \%
$$

\section{Numerical Economic Analysis}

\subsection{Inputdata}

Current average price of industrial electrical energy in Serbia, 2015 is 0.0463 [Euro/ kWh].

Predicted average consumption of clean water $5220[\mathrm{~kg} / \mathrm{h}]$

Power for heating $5220[\mathrm{~kg} / \mathrm{h}]$ clean water from $13.8\left[{ }^{\circ} \mathrm{C}\right]$ to $55\left[{ }^{\circ} \mathrm{C}\right]$ is $248[\mathrm{~kW}]$.

Nominal working hours for two shifts per day is 16 hours.

Coefficient utilization of nominal working hours is about 0.8 .

\subsection{Calculation}

Consumption of hot clean water is a stochastic quantity because filling the four washing machines is periodical. Determination of the necessary clean hot water quantity was carried out, together with the amount estimation and the effective time of consumption.

Nominal consumption of heat energy $248 \mathrm{~kW} \cdot 0.8 \cdot 16 \mathrm{~h}=3174[\mathrm{kWh} /$ day $]$

Predicted number of workdays a year

(52- 4 ) $[$ week/ year $] \cdot 5$ [day/week $]=240$ [day/year $]$ 
Annual consumption of heat energy

$3174[\mathrm{kWh}] \cdot 240[$ day/ year $]=761760[\mathrm{kWh} /$ year $]$

Maximum consumed electrical energy annually of all components of the recovery system

$38,2[\mathrm{~kW}] \cdot 0.8 \cdot 16[\mathrm{~h}] \cdot 240[$ day/ year $]=117350[\mathrm{kWh} /$ year $]$

Annual electrical energy savings of the recovery system

761760 [kWh /year] -117 350 [kWh/year ] = 644410 [kWh/year]

Value of the saved electrical energy per year

644410 [kWh / year] 0.0463 [euro / kWh] = 29836 [Euro / year]

Approximate total necessary investment for realization of the recovery system:

$60000[$ Euro]

Expected payback period of the invested money when an electrical heater recovery system is used for clean water heating:

$60000[$ Euro] / 29836 [euro/year] = 2.01 [year]

\section{Results in the Graphics}

Numerically obtained results in graphical presentation.

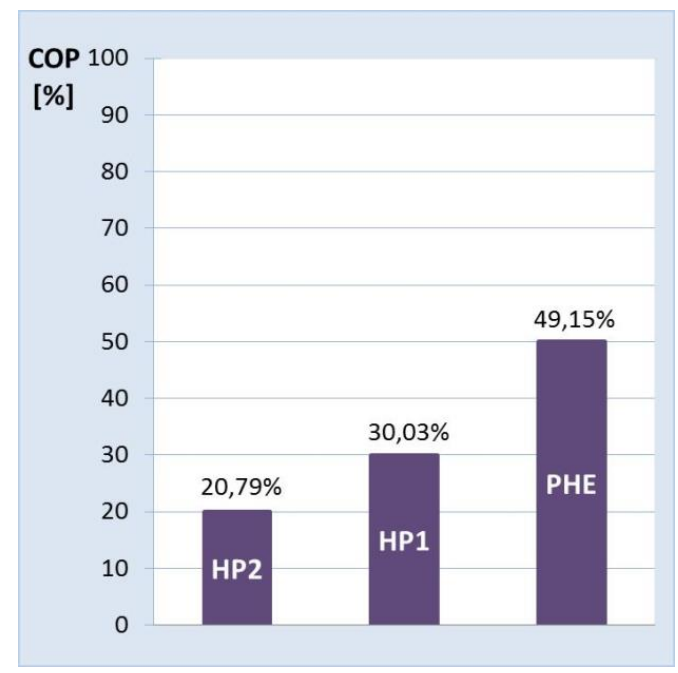

Figure 2

The percentage share of individual components in the heat recovery process: PHE-plate heat exchanger 49.15\%, HP1- heat pump filled with R 407C 30.03\%, HP2- heat pump filled with R 134a $20.79 \%$ 


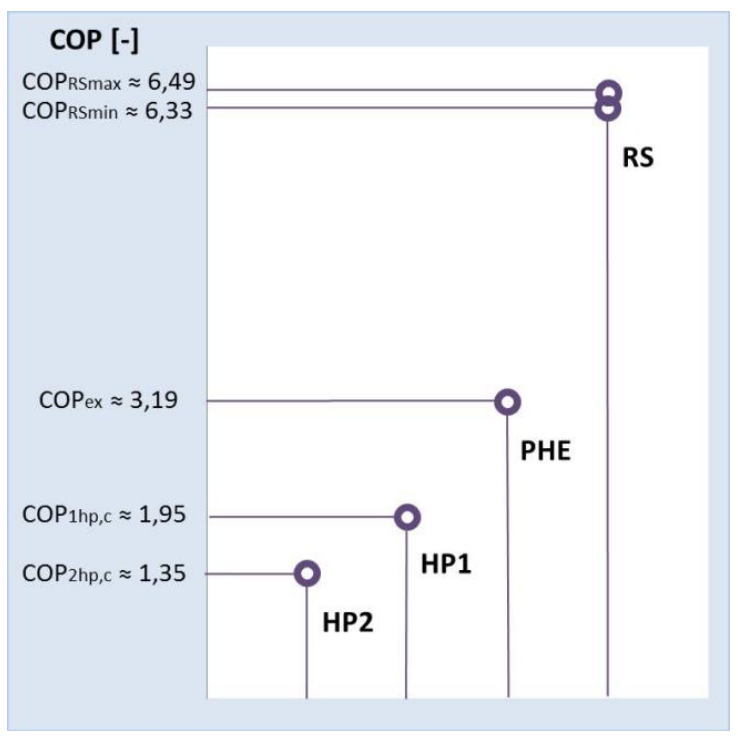

Figure 3

$\mathrm{COP}$ of the components and of complete heat recovery system

\section{Conclusion}

The recovery system described in this article is quite efficient both in energetic and economic terms.

- The system's total coefficient of performance is very high: COP is from 6 to 6.5

- The component's partial COPs are the following: 3.19 [-]for the heat plate exchanger, 1.95 for the heat pump1, 1.35 for the heat pump2

- The total energy savings expressed in percentages:

Minimally (1-1/6) $\quad 100 \%=83.3 \%$ or

Maximally $(1-1 / 6,5) 100 \%=85 \%$

- The energy savings of the components in percentages: Plate heat exchanger 49\%, low temperature heat pump $30 \%$, high temperature heat pump $21 \%$

- The payback period of the investment is relatively short, about 2 years.

In addition to energy and economic advantages this solution is also very favorable in terms of environment protection. The recovery system protects the environment on direct and indirect way.

Directly:

1) The waste water does not enter in the sewer while it is still hot.

2) The waste water is cleaned by filtration before getting out of the recovery system. 
Indirectly:

1) By saving a great quantity of heat energy the electrical energy use is significantly reduced.

2) Less use of electricity, less working power plant the result is a reduced $\mathrm{CO}_{2}$ emission.

The presented results are valid for the economic situation in Serbia, 2015.

The task of further research is to find the optimal structure and dimensions of the system's thermal and energy components in order to improve the energy and economic efficiency of the new heat recovery system.

\section{References}

[1] Fangtian Sun, Lin Fu, Jian Sun and Shigang Zhang:"A New Waste Heat District Heating System with Combined Heat and Power (CHP) Based on Ejector Heat Exchangers and Absorption Heat”. IJ. Energy Vol. 69 (2014) pp. 516-524

[2] Jian Sun, Lin Fu, Fangtian Sun and Shigang Zhang: "Study on a Heat Recovery System for the Thermal Power Plant Utilizing Air Cooling Island”. IJ. Energy Vol. 74 (2014) pp. 836-844

[3] Marija S. Todorovic, Jeong Tai Kim:” In Search for Sustainable Globally Cost-Effective Energy Efficient Building Solar Syste1.m - Heat Recovery Assisted Building Integrated PV Powered Heat Pump for Air-Conditioning, Water Heating and Water Saving". Energy and Buildings, Volume 85, December 2014, pp. 346-355

[4] Bicui Ye, Jun Liu, Xiangguo Xu, Guangming Chenand Jiao Zheng:"A New Open Absorption Heat Pump for Latent Heat Recovery from Moist Gas". Energy Conversion and Management, Volume 94, April 2015, pp. 438-446

[5] Ming Qu, Omar Abdelaziz and Hongxi Yin:'New Configurations of a Heat Recovery Absorption Heat Pump Integrated with a Natural Gas Boiler for Boiler Efficiency Improvement”. Energy Conversion and Management, Volume 87, November 2014, pp. 175-184

[6] Zhao Yang, Yang Zhuo, Luo Ercang and Zhou Yuan: "Travelling-Wave Thermo Acoustic High-Temperature Heat Pump for Industrial Waste Heat Recovery”. Energy, Volume 77, 1 December 2014, pp. 397-402

[7] J. Nyers, L. Garbai, A. Nyers: "Analysis of Heat Pump's Condenser Performance by means of Mathematical Model". International J. Acta Polytechnica Hungarica, Vol. 11, No. 3, pp. 139-152, 2014, DOI: 10.12700/APH.11.03.2014.03.9

[8] György Györök: A Special Case of Electronic Power Control of Induction Heating Equipment. Acta Polytechnica Hungarica Vol. 11, No. 5, pp 235246, 2014. DOI: 10.12700/APH.11.05.2014.05.14 
[9] László Kajtár, Miklós Kassai, László Bánhidi: Computerised Simulation of the Energy Consumption of Air Handling Units, 2011, Energy and Buildings, ISSN: 0378-7788, (45) pp. 54-59

[10] Miklos Kassai: Effectiveness and Humidification Capacity Investigation of Liquid-to-Air Membrane Energy Exchanger under Low Heat Capacity Ratios at Winter Air Conditions. Journal of Thermal Science. Vol. 24, No. 4, pp. 391-397, DOI: 10.1007/s11630-015-0800-4 (2015)

[11] S. Pavlović, D. Vasiljević, V. Stefanović, Z. Stamenković, S. Ayed: "Optical Model and Numerical Simulation of the New Offset Type Parabolic Concentrator with Two Types of Solar Receivers". Facta Universitatis Series: Mechanical Engineering Vol. 13, No 2, pp. 169-180, 2015

[12] B. Bokor, L. Kajtár: Luftkollektoren: Nutzung der Sonnenenergie in der Gebäudelüftung e-nova Internationaler Kongress 2014, Nachhaltige Gebaude, 13-14. November 2014. Pinkenfeld, pp. 305-310, ISBN: 978-37011-0316-4

[13] M. Todorović, D. Živković, M. Mančić, D. Milčić: Dynamic Behaviour of Hot Water Boilers during Start UP. Facta Universitatis Series: Mechanical Engineering Vol. 12, No. 1, pp. 85-94 (2014)

[14] F. Kalmár, GY. Csomós, Á. Lakatos: "Focus on Renewable Energy (energy policy)_Editorial"International Review of Applied Sciences and $\begin{array}{lllll}\text { Engineering } & 4 & (1), & 95-95 & \text { (2013) }\end{array}$ http://dx.doi.org/10.1556/IRASE.4.2013.1.13

[15] Magyar Zoltán, Révai Tamás: Thermal Insulation of the Clothing $2^{\text {nd }}$ Royal Hungarian Army in Winter Campaign in the Light of Thermal Manikin Measurements. Acta Polytechnica Hungarica 11:(7) pp. 197-207 (2014)

[16] Á. Lakatos, S. Szigeti, F. Kalmár: "Measurement of the Water Uptaking Capability of a Thermal Insulating Paint". International Review of Applied Sciences and Engineering 4 (2), 157-161 (2013) DOI: http://dx.doi.org/10.1556/IRASE.4.2013.2.10 